\title{
Treatment of psoriasis with zinc sulphate cream $2.5 \%$ in comparison with clobetasol propionate cream
}

\author{
K Al-Hamdi, M Al-Waiz, L Al-Kinani
}

\section{Citation}

K Al-Hamdi, M Al-Waiz, L Al-Kinani. Treatment of psoriasis with zinc sulphate cream $2.5 \%$ in comparison with clobetasol propionate cream. The Internet Journal of Dermatology. 2006 Volume 6 Number 1.

DOI: $\underline{10.5580 / 918}$

\begin{abstract}
Background: Psoriasis is a common, distressing dermatological disease with no unique curative systemic or topical treatment. Zinc has been described in many literatures as an effective treatment for many dermatological diseases so that zinc sulphate is used in this study as a topical treatment of psoriasis.

Objectives: To evaluate the effectiveness of topical zinc sulphate cream $2.5 \%$ in treatment of psoriasis, in comparison with clobetasol propionate cream $0.05 \%$ alone and zinc sulphate $2.5 \%$ plus clobetasol propionate $0.05 \% \mathrm{cream}$.

Patients and Methods: A total 131 patients with psoriasis vulgaris who were consulting Department of Dermatology and Venereology of $\mathrm{Al}$-Sadder teaching hospital in Basrah during a period from Dec. 2004 through Aug. 2006 were enrolled in this study. They were $65(49.6 \%)$ females and 66(50.4\%) males, with female: male ratio 1:1.1. Patients were divided into three groups; patients in group I were treated with zinc sulphate cream $2.5 \%$, while group II patients were treated with clobetasol propionate cream $0.05 \%$ and patients in group III were treated with zinc sulphate $2.5 \%$ plus clobetasol propionate cream. All patients were followed up for 12 weeks.

$>$ Results:

The Study showed that Zinc sulphate cream induced marked remission in about $53.3 \%$ of the cases; with relapse rate $75 \%$ three weeks after cessation of treatment, while topical clobetasol propionate induced marked remission in $74.4 \%$ of the cases with relapse rate $78 \%$ three weeks after stopping the treatment, further more the combination of zinc sulphate with clobetasol propionate cream induced marked remission in $83.7 \%$ of the cases, with relapse rate $77.8 \%$ three weeks after cessation of treatment . Mild burning sensation at the treated site is the only side effect of zinc sulphate which was reported in $26.1 \%$ of the cases.

Conclusion: Zinc sulphate is an effective treatment of psoriasis but the combination of zinc sulphate plus clobetasol propionate was proved to be more effective than zinc sulphate and clobetasol propionate alone and zinc sulphate did not decrease the relapse rate.
\end{abstract}

\section{INTRODUCTION}

Psoriasis: Psoriasis is a common, chronic, relapsing, genetically determined, inflammatory and proliferative disease of the skin. It affects about 2-3\% of the world's population $\left(_{1}\right.$ ) .while, In Iraq, the incidence was $1.5 \%$ ${ }_{2}$ ).Nowadays, psoriasis is considered as an immunologically mediated disease towards not fully defined antigen $\left({ }_{3}\right)$. In spite of advances represented by biologics, topical treatment will probably remain the mainstay of psoriasis therapy for most patients $\left(_{4}\right.$ ) but; unfortunately there is no unique curative systemic or topical treatment for the disease.

Zinc: Is one of the essential trace elements $\left.{ }_{5}\right)$. It's an important element that is found in every cell in the body; more than 300 enzymes in the body need zinc in order to function properly $\left.{ }_{6}\right)$. Zinc has been used successfully in the treatment of many skin diseases such as Cutaneons leishmaniasis $\left({ }_{7,8},{ }_{9}\right)$ and Viral warts $\left({ }_{10},{ }_{11}\right)$, where it was found to be safe, noncostly and effective therapy.

\section{PATIENTS AND METHODS}

This is a single blind comparative, therapeutic, out patient based study where 131 patients with mild-moderate psoriasis, consulting the Department of Dermatology and Venereology in Al -Sadder teaching hospital in Basrah during the period from Dec. 2004 through Aug.2006, were 
enrolled in this study. They were $65(49.61 \%)$ females and $66(50.4 \%)$ males, with female: male ratio $1: 1.1$. Their ages ranged from $5-75$ years with a mean of $29.3 \pm 16$. The patients were divided into three groups according to their topical treatments, as follows:-

Group I: Included patients who were treated with zinc sulphate cream $2.5 \%$. They were 45 patients; 22 (48.9\%) females and $23(51.1 \%)$ males. Their ages ranged from 5-65 years with a mean of $34 \pm 20.6$ years. Their mean base line PASI score was $6.8 \pm 4.7$.

Group II: Included patients on clobetasol propionate $0.05 \%$ cream. They were 43 patients; 22 (51.2\%) females and 21 (48.8\%) males. Their ages ranged from 5-73 years with a mean of $29.3 \pm 16$. Their mean base line PASI score was 8.6 \pm 5.5 .

Group III: Included patients on clobetasol propionate plus zinc sulphate cream $2.5 \%$. They were 43 patients; 21 $(48.8 \%)$ females and $22(51.2 \%)$ males. Their ages ranged from 6-65 years with a mean of $27.4 \pm 17$ years. Their mean base line PASI score was $8 \pm 5.7$.

All patients were interviewed and detailed history were obtained including, age, sex, occupation, residence , duration of disease, medical history, family history, history of previous treatment and smoking .

PASI (psoriasis Area and Severity Index) score was employed to evaluate the disease extent and to monitor the therapeutic response. PASI score was measured before, during and after treatment $\left({ }_{12},{ }_{13},{ }_{14}\right)$.

Statistical analysis: For the determination of the statistical significance among different variables, descriptive statistics (like mean and standard deviation) were used together with analytic statistics like chi-square, t-test and $\mathrm{Z}$ test.

\section{RESULTS}

A total of 131 patients were enrolled in this study; 65 (49.6\%) females and $66(50.4 \%)$ males. Their ages ranged from 5-73 years. Most patients were in the second and third decades of life. Family history of psoriasis was positive in $45(34.4 \%)$ of patients. Nail changes were found in $34.4 \%$ of cases. Itching was reported in about $89.3 \%$ of patients. It varied in severity from mild -severe. Itching was moderate in severity in about $48.1 \%$ of cases, while in the remaining $29.9 \%$, and $21.4 \%$ it was mild and severe respectively.

The response to treatment in different groups (Table 1, 2):
The patients were subdivided into three groups according to their response to treatments as follow:

For group 1

A- Patients who achieved a good response with a reduction in PASI score $\geq 50 \%$ were $24(53.3 \%)$.

B- Patients who achieved partial response with a reduction in PASI score ranged from 25-49\% were 13 (28.9\%).

C- Eight (17.8\%) patients had poor response with a reduction in PASI score $<25 \%$.

For group II:

A- Thirty two (74.4\%) patients showed a good response with a reduction in PASI score $\geq 50 \%$.

B- Partial response was reported in eight (18.6\%) patients, with a reduction in PASI score ranged from $25-49 \%$.

C- Poor response was noticed in three $(6.9 \%)$ patients.

For group III

A- It has been noticed that $36(83.7 \%)$ of patients achieved good response.

B- Partial response was reported in five (11.6\%) patients.

C- Poor response was recorded in two (4.65\%) patients only.

In group I, the mean reduction in PASI score was $39.1 \%$ at 4 weeks from the mean base line PASI score, meanwhile the reduction in PASI score at 8 and 12 weeks were $58 \%$ and $62.3 \%$ respectively.

In group II the mean reduction in PASI score was $51.2 \%$ from the mean base line PASI ( $8.6 \pm 5.5$ ) at 4 weeks, while the reduction in PASI score at 8 week and 12 weeks were $60.5 \%$ and $62.8 \%$ respectively.

In group III , the reduction in mean of PASI score was $62.8 \%$ from the mean base line PASI score $(8 \pm 5.1)$ at 4 weeks, while the reduction in PASI at 8 weeks and 12 weeks were $76.3 \%$ and $85 \%$ respectively.

The difference in the degree of improvement in the three groups at 12 weeks of treatment were statistically significant with P. value $<0.05 \%) \%$ ) but it is clearly seen that topical treatment with a combination of zinc sulphate $2.5 \%$ and clobetasol propionate cream $0.05 \%$ induced the best results 
and with relatively shorter period of time.

Duration of remission and relapse rate (table 3):

In group I, eight ( $33.3 \%$ ) cases were relapsed at the end of the first week, while, four ( $16.1 \%)$ cases relapsed at the end of second week and six ( $25 \%$ ) cases relapsed at the end of the third week after stopping the treatment. The relapse rate was $(75 \%)$ cases.

In group II, $12(31.5 \%)$ cases were relapsed at the end of first week, six $(18.8 \%)$ cases relapsed at the end of second week and seven $(21.9 \%)$ cases relapsed at the end of third week after stopping the treatment. The relapse rate was $(78 \%)$ cases.

In group III, at the end of first week, 10 cases (21.8\%) were relapsed, while seven $(19.9 \%)$ cases were relapsed at the end of second week and $11(30.6 \%)$ cases were relapsed at the end of third week. The relapse rate was $(77.8 \%)$.

The difference in relapse rate between the three modalities of treatments is not statistically significant but those patients who were treated with the combination treatment relapsed after relatively longer period of time ( $\geq 3$ weeks).

Further more, the present work showed regional variation in the response to the three modalities of treatment used where scalp and truncal psoriatic lesions showed a higher degree of reduction in the mean PASI score values than lesions involving the extremities in response to zinc sulphate cream alone and the combination therapy which were, in turn, higher than the reduction in PASI score values of the lesions treated with clobetasol propionate alone.

Side effects: A bout 12 (26.1\%) of cases treated with zinc sulphate cream 2.5 showed a transient, mild burning sensation at the initial time of application, which disappeared after few minutes.

Defaulted rate: Twenty two cases $(16.8 \%)$ were defaulted from the treatment.
Figure 1

\begin{tabular}{|c|c|c|c|c|}
\hline P.Values & $\begin{array}{l}\text { Zinc sulphate } \\
2.5 \% \\
\text { +clobetasol } \\
\text { propionate } \\
\text { cream }\end{array}$ & $\begin{array}{l}\text { Clobetasol } \\
\text { propionate } \\
\text { cream }\end{array}$ & $\begin{array}{l}\text { Zinc } \\
\text { sulphate } \\
\text { cream } \\
2.5 \%\end{array}$ & weeks \\
\hline 0.284 & $8 \pm 5.7$ & $8.6 \pm 5.5$ & $6.9 \pm 4.7$ & Weeks \\
\hline 0.207 & $4.1 \pm 3$ & $5.4 \pm 4.1$ & $5.4 \pm 3.9$ & 2Weeks \\
\hline 0.067 & $\begin{array}{l}2.9 \pm 2.5 \\
62.8 \%\end{array}$ & $\begin{array}{l}4.2 \pm 3.6 \\
51.2 \%\end{array}$ & $\begin{array}{l}4.2 \pm 2.7 \\
39.1\end{array}$ & 4 weeks \\
\hline 0.053 & $2.4 \pm 2.3$ & $3.6 \pm 3.4$ & $3.6 \pm 2.5$ & 6 weeks \\
\hline 0.034 & $\begin{array}{l}1.9 \pm 2 \\
76.3 \%\end{array}$ & $\begin{array}{l}3.4 \pm 3 \\
60.5 \%\end{array}$ & $\begin{array}{l}2.9 \pm 2.3 \\
58 \%\end{array}$ & 8 weeks \\
\hline 0.012 & $1.5 \pm 1.7$ & $3.5 \pm 3.6$ & $2.5 \pm 2$ & 10 weeks \\
\hline 0.013 & $\begin{array}{l}1.2 \pm 1.6 \\
85 \%\end{array}$ & $\begin{array}{l}3.2 \pm 2.7 \\
62.8 \% .3\end{array}$ & $\begin{array}{l}2.6 \pm 2 \\
62.3 \%\end{array}$ & 12 weeks \\
\hline & $<0.05$ & $<0.05$ & $<0.05$ & P Values \\
\hline
\end{tabular}

At different Weeks for different modalities of treatments

\section{Figure 2}

Table 2: showing the degree of response in different modalities of treatments

\begin{tabular}{|c|c|c|c|}
\hline \multirow[t]{2}{*}{ Improvement } & \multicolumn{3}{|l|}{ Group } \\
\hline & 1 & 2 & 3 \\
\hline A & $2453.3 \%$ & $3274.4 \%$ & $3683.7 \%$ \\
\hline B & $1328.9 \%$ & $818.6 \%$ & $511.6 \%$ \\
\hline C & $817.8 \%$ & $36.9 \%$ & $24.65 \%$ \\
\hline Total & $45100 \%$ & $43100 \%$ & $43100 \%$ \\
\hline
\end{tabular}

$\mathrm{X} 2=10.78$ 4df $\mathrm{P}<0.05$
A. good response cases with PASI score reduction $\geq 50$
B. Partial response cases with PASI score reduction $25-49 \%$
C. Poor response cases with PASI score reduction $<25 \%$ 


\section{Figure 3}

Table 3: Showing relapse rate for different modalities of treatments

\begin{tabular}{|l|l|l|l|l|l|}
\hline Group & Total & $<1$ wk & $1-2$ wks & $\geq 3$ wks & Relapse rate \\
\hline $\begin{array}{l}\text { Zinc sulphate cream } \\
2.5 \%\end{array}$ & 24 & $833.3 \%$ & $416.7 \%$ & $625 \%$ & $1875 \%$ \\
\hline $\begin{array}{l}\text { Clobetasol } \\
\text { propionate cream }\end{array}$ & 32 & $1237.5 \%$ & $618.8 \%$ & $721.9 \%$ & $2578 \%$ \\
\hline $\begin{array}{l}\text { Zinc+ Clobetasol } \\
\text { propionate cream }\end{array}$ & 36 & $1027.8 \%$ & $719.9 \%$ & $1130.6 \%$ & $2877.8 \%$ \\
\hline
\end{tabular}

Total* No. of cases with good response. $P>0.05$

\section{DISCUSSION}

Psoriasis is a common, chronic, relapsing, distressing skin disease of unknown aetiology $\left.{ }_{3}\right)$. Recently psoriasis is thought to be an immunologically mediated disease where Tcells play an important role in its pathogenesis $\left(_{4}\right)$. Zinc sulphate has been used as immunomodulator in the treatment of many dermatological problems such as alopecia areata $\left({ }_{15}\right)$ and Cutaneons leishmaniasis $\left({ }_{7},{ }_{8}\right)$, yet trial of oral zinc sulphate proved to be ineffective in treatment of psoriasis ${ }_{16}$ ). Recent reports found that serum zinc is lower in psoriatic patients in comparison with non psoriatic ones $\left({ }_{17},{ }_{18}\right)$. Accordingly zinc sulphate has been used in this study as a topical treatment alone or in combination with clobetasol propionate cream.

The results of present work showed that topical zinc sulphate cream achieved marked remission in about $53.3 \%$ of cases at 12 weeks of treatment but the onset of action seemed to be slow as the patients started to notice improvement after 8 weeks of treatment. On the other hand, topical treatment with clobetasol propionate cream induced marked remission in about $74.4 \%$ of cases. The improvement becomes clinically evident for the patients and treating dermatologist at 4 weeks of treatment.

Further more, the use of a combination of both zinc sulphate $2.5 \%$ and clobetasol propionate cream $0.05 \%$ achieved marked remission in about $83.7 \%$ of the treated patients. Marked improvement was observed at 4 weeks after the onset of the treatment.

The difference in the degree of improvement in the three groups at 12 weeks of treatment were statistically significant with P. value $<0.05 \%$ ).

On the basis of the above mentioned results it is clearly seen that topical treatment with a combination of zinc sulphate $2.5 \%$ and clobetasol propionate cream $0.05 \%$ induced the best results and with relatively shorter period of time .

The study also showed that $75 \%$ of those patients who achieved marked improvement with zinc sulphate cream relapsed three weeks after cessation of treatment, while $78 \%$ of those treated with clobetasol propionate cream relapsed within the same period. On the other hand, psoriasis in those patients treated with a combination of zinc sulphate and clobetasol propionate relapsed in $77.8 \%$.

The difference in the degree of relapse rate in the three groups were statistically not significant, indicating that the three modalities of topical treatment that have been used in this study doesn't affect the relapse rate of the disease and neither zinc sulphate, nor the combination of zinc and clobetasol propionate was superior on clobetasol propionate alone but the study was also showed that those patients who were treated with the combination treatment relapsed after relatively longer period of remission ( $\geq 3$ weeks ) in comparison with patients treated with clobetasol propionate cream where the majority relapsed 1 week after cessation of treatment .

Also the study showed regional variation in the response to the three modalities of treatment used where scalp and truncal psoriatic lesions showed significantly more reduction in the mean PASI score values than lesions involving the extremities in response to zinc sulphate cream alone and the combination therapy which were, in turn, higher than the reduction in PASI score values of the lesions treated with clobetasol propionate alone.

On the other hand, the regional variation in response to the combination therapy is much less evident than treatment to the other two modalities, where lesions at all regions responding remarkably to the combination therapy with no significant statistical differences. This result is in contrast to that mentioned in literature where the scalp and the extremities are considered as resistant sites to other modalities $\left({ }_{1}\right)$.

Unfortunately, to the best of our knowledge, no previous studies about the same subject have been done to compare our results with.

For combination therapy our results is similar to that of other study using a combination of clobetasol propionate with zinc pyrithione where the latter is thought to augment the effectiveness of clobetasol $\left(_{19}\right)$.

In comparison with other study ,the rate of marked remission 
achieved by zinc sulphate cream is nearly similar to that produced by calcipotriol ointment (53.3 versus $53.8 \%$ respectively), while Daivobet (containing the combination of calcipotriol and betamethasone dipropionate ointment) induced a higher remission rate than zinc sulphate cream $\left(88.8 \%\right.$ vs. $53.3 \%$ respectively) $\left(_{20}\right)$.

The study showed that zinc sulphate cream is a safe topical therapy with no reported side effects a part from mild burning sensation which was reported in a bout $26.1 \%$ of cases at the initial time of application. This observation let zinc sulphate cream superior than clobetasol propionate cream which cause many well known local and systemic side effects . In addition, steroid is shown to loss its effectiveness shortly after the onset of the treatment as a result of tachyphylaxis phenomenon, in contrast to zinc sulphate in which the effectiveness is increased steadily with the duration of topical use.

Zinc sulphate as a treatment of psoriasis is thought to be through many mechanisms:

1- Immunological:

a- As immunomodulator $\left({ }_{15},{ }_{18}\right)$ : Zinc sulphate may actually cause suppression of unwanted immune reactions.

b- Patients with active psoriasis vulgaris had a significant increase in neutrophil random migration and directed chemo taxis. Zinc sulphate treatment restores both the random migration and directed chemo taxis to normal values (zinc sulphate modifies neutrophil inflammatory potential) $\left({ }_{16}\right)$.

c- Zinc sulphate may correct the imbalance between Th1 and $\mathrm{Th}_{2}$ cytokines in the psoriatic lesion $\left({ }_{21}\right)$.

2- Anti inflammatory effect through inhibition of prostaglandins $\left({ }_{22},{ }_{23}\right)$.

3- Anti proliferative mechanism of action may involve the regulation of DNA transcription factors (containing zinc finger binding domains $)\left({ }_{24,25}\right)$.

4- It is also well known that a deficiency of zinc produce a disease state (Acrodermatitis enteropathica) that include Psoriasiform lesion $\left({ }_{26},{ }_{27}\right)$.

5- Anti oxidant activity:

Reactive oxygen species have been implicated in the pathogenesis of various hyperproliferative and inflammatory disease. Studies showed that the expression of the antioxidant enzyme super oxide dismutase (mn SOD) was consistently higher in lesional psoriatic skin as compared to uninvolved skin $\left({ }_{28},{ }_{29}\right)$.

6- On high concentration, Zinc has a direct cytotoxic effect and is well $\mathrm{k}$

\section{CONCLUSIONS}

1. Zinc sulphate cream is shown to be an effective treatment of psoriasis as it induced remission in $53.3 \%$ of cases but with relatively delayed onset of action.

2. The combination of zinc sulphate plus clobetasol propionate proved to be better than clobetasol propionate and zinc sulphate alone as it induced marked and complete remission of psoriasis in about $83.7 \%$ of cases.

3. Zinc sulphate cream is found to cause very mild and transient side effects in comparison with clobetasol propionate cream.

\section{CORRESPONDENCE TO}

Assistant Prof. Khalil I Al-Hamdi MD PhD, The head of Department of Dermatology and Venereology, Basrah medical college. Email: khalil_hamdi2003@yahoo.com

\section{References}

1. C E M Griffiths, R D R Camp\& J N W Baker. Psoriasis, In: Tony Burns, Breathnach, Cox, Griffiths. Rooks Text book of Dermatology.7th Ed London; Blackwell Ltd; 2004; 35:35.1-35.69.

2. Al Nuamy S. Epidemiology and HLA typing of psoriasis in Iraq. A study submitted to Universityof Baghdad,College ofMedicine. Diploma Thesis 1988; 45.

3. T Kormeili, N J Lowe, and P S Yamauchi. Psoriasis: Immunopathogenesis and evolving immunomodulators and systemic therapies; U.S.Experience.Br J Dermatol 151(1):3-15, 2004.

4. Gerald Krueger and Charles N. Ellis. Psoriasis- recent advances in understanding its pathogenesis and treatment. J Acad Dermatol 2005; 53: 94-100.

5. Mayes P.A. Nutrition, Digestion and Absorption. In:

Murry R.. Granner D. Harpers Biochemistry.21 ed. Appleton and lange. $1996: 625-635$.

6. Falchuk KH. Disturbance in Trace Elements In Fanci A.S. Braunwald E. Harrison's Princiles of Internal medicine. 14 ed. Mc Graw- Hill Companies. Inc. 1998; 80:489-492.

7. Sharquie KE, A1-Azzawi K. Intralesional therapy of cutaneous leishmaniasis with $2 \%$ zinc sulphate solution. J Pan-Arab Leaque Dermatologist 1996;7:41-46.

8. Sharquie KE, NajimRA and Farjou IB. A comparative controlled trial of intralesionally-administered zinc sulphate, hypertonic sodium chloride and pentavalent antimony compound against acute cutaneous leishmaniasis.

Clin.Exp.Dermatol 1997; 22: 169-73.

9. Sharquie KE, Najim RA, AL- Timimi DJ, Farjou IB. Oral 
zinc sulphate in the treatment of acute cutaneous leishmaniasia: Clin. Exp.Dermatol. 2001; 26: 21-26. 10. Al-Gurairi F Al-Waiz M, Sharquie KE. Oral zinc sulphate in the treatment of recalcitrant viral warts: randomized placebocontrolled clinical trial. Br.J.Dermatol. 2002; 146: 423-31.

11. Al-Timimi TH. Oral zinc sulphate in the treatment of anogenital warts among Iraqi females. A thesis submitted to the Iraqi Board for Medical Specialization, Dermatology and Venereology. 2002.

12. Dave's M. The Psoriasis Area and Severity Index: Internet 2003. http://www.Dave'sPsoriasisInfo.com. 13. Carlin CS, Feldman SR, Krueger JG, MenterA, KruegerGG. A 50\% reduction in the Psoriasis area and Severity Index (PASI) is a clinical significant end point in the assessment of psoriasis. J Am Acad Dermatol.2005 Sep; 53(3):547-51.

14. Tara Rolstad, Gerald Krueger .Definitions of Measures of Effect Duration for Psoriasis treatments .Arch Dermatol. 2005; 141:82-84.

15. Lutz G, Kreysel HW. Selective changes in lymphocytic differentiation antigen in the peripheral blood of patients with

alopecia areata treated with oral zinc. Z Hautkr 1990; 65:

$132-4$,

13. $7-8$.

16. Leibovici V ,Statter M, Weinrauch L, Tzfoni E

,Matzner Y. Effect of zinc therapy on neutrophil chemotaxis in psoriasis. Isr J Med Sci. 1990 Jun; 26(6):306-9.

17. Saxna N, Sharma RP, Singh VS. A study of serum zinc and copper levels in psoriasis. Indian J Dermatol Venereol Leprol 1990; 56:216-8.

18. Mc Millan C, Rowe D. Plasma zinc in psoriasis:

Relationship to surface area involvement.Br J Dermatol $1983 ; 108: 301-5$.

19. Charles E. The Temporal Dermatohistopathologic Examination of Human psoriatic skin treated with a novel topical liquid formulation containing clobetasol propionate. Internet 2003 .Dave's Psoriasis Info-Zinc Index .htm. 20. Ansty AV, Krugballek .Retrospective assessment of PASI 50 and PASI 75 attainment with a calcipotriol betamethasone dipropionate ointment. Int J Dermatol 2006; 45(6):970-5

21. Prasad AS. Wayne State University, University Health Center,Detroit, MI 48201,USA.Effects of zinc deficiency on Th1 and Th2 cytokine shifts. J Infect Dis. 2000 Sep; 182: 62-8.

22. Clermensen OJ, SiggaardJ. Psoriatic arthritis treaed with zinc sulphate. Br.J.Dermatol. 1980; 103:411-5.

23. Dr Bob Lawrence's advice .The Zinc Taste Test.The Multiple Sclerosis Resource Cent .Wednesday, 05 January 2005.

24. Bernstein BE, Hoffman RC, Klevit RE: Sequenc specific DNA recognition by Cys2, His2 zinc fingers .Ann NY Acad Sci 1994; 726:92-104.

25. Rhodes D, and Klug A: Zinc fingers Sci .Am ,1993 :268:56-65.

26. Graves ,K.,Kestenbaum T, and KaliveJ.hereditary acrodermatiis enteropathica in adult. Arch Dermatol 116:5,562-564, 1980.

27. Neldner, K. H., Zinc deficiency and the skin. In: Maddin S. Ed., Current Dermatological Therapy. WB Saunders \& Co. Philadelphia 1982 PP. 50-54.

28. Rostan, Elizabeth F, De Buys, Holly V, Madey, Doren L, Pinnel, Sheldon R. Evidence supports zinc as an important anti oxidant for skin. Int.J. Dermatol 2002; 41(9).

29. Lontz W; Sirsjo A; Liu W; Lindberg M; Rollman O; Torma H. Increased mRNA expression of manganese superoxide dismutase in psoriatic skin lesions and cultured human keratinocytes exposed to $1 \mathrm{~L}-1$ beta and TNF- alPha Free Radical Biology and medicine, 1995 feb, 18(2): 349-55. 30. Litaka $M$,Kakinuma $S$ and Fujmaki S .Induction of apoptosis and necrosis by zinc in human thyroid cancer cells lines.J Endocrinol 2001;169(2) :417-24. 


\section{Author Information}

Khalil I. Al-Hamdi, M.D., Ph.D.

Assistant Prof. Consultant dermatology, Head, Department of Dermatology and Venereology, Basrah Medical College.

\section{Makram M. Al-Waiz, MBChB DDSc PhD}

Department of Dermatology and Venereology, College of Medicine, Baghdad University

\section{Laith C. Al-Kinani, MBChB}

Department of Dermatology and Venereology, Al-Sadder Teaching Hospital in Basrah 